\title{
Benign Uterine Corpus Neoplasm
}

National Cancer Institute

\section{Source}

National Cancer Institute. Benign Uterine Corpus Neoplasm. NCI Thesaurus. Code C3608.

A non-metastasizing neoplasm that arises from the uterine corpus. Representative examples include leiomyoma, adenomyoma, endometrial stromal nodule, and endometrial polyp. 